\title{
Actuation Spray Valve Device
}

National Cancer Institute

\section{Source}

National Cancer Institute. Actuation Spray Valve Device. NCI Thesaurus. Code C149949.

A valve device on a container that delivers a precise spray dose of contents by actuation. 